\title{
Neurodevelopmental Disorders of Children Screened by The Infantile Health Promotion System
}

\author{
Seong Woo Kim, M.D., Zee-A Han, M.D., Ha Ra Jeon, M.D., Ja Young Choi, M.D., \\ Hee Jung Chung, M.D. ', Young Key Kim, M.D. ${ }^{2}$, Yeo Hoon Yoon, M.D. ${ }^{3}$ \\ Departments of Physical Medicine and Rehabilitation, ${ }^{1}$ Pediatrics, ${ }^{2}$ Psychiatry, \\ National Health Insurance Corporation Ilsan Hospital, Goyang 410-719, \\ ${ }^{3}$ Department of Rehabilitation Medication, Yonsei University College of Medicine, Seoul 135-720, Korea
}

\begin{abstract}
Objective To perform an in depth evaluation of children, and thus provide a systematic method of managing children, who after infantile health screening, were categorized as suspected developmental delay.

Method 78 children referred to the Developmental Delay Clinic of Ilsan Hospital after suspected development delay on infantile health examinations were enrolled. A team comprised of a physiatrist, pediatrician and pediatric psychiatrist examined the patients. Neurological examination, speech and cognitive evaluation were done. Hearing tests and chromosome studies were performed when needed clinically. All referred children completed K-ASQ questionnaires. Final diagnoses were categorized into specific language impairment (SLI), global developmental delay (GDD), intellectual disability (ID), cerebral palsy (CP), motor developmental delay (MD) or autism spectrum disorder (ASD).

Results 72 of the 78 patients were abnormal in the final diagnosis, with a positive predictive value of $92.3 \%$. Thirty (38.4\%) of the 78 subjects were diagnosed as GDD, 28 (35.8\%) as SLI, $5(6.4 \%)$ as ASD, 9 (12.5\%) as MD, and 6 $(7.6 \%)$ as normal. Forty five of the 78 patients had risk factors related to development, and 18 had a positive family history for developmental delay and/or autistic disorders. The mean number of abnormal domains on the K-ASQ questionnaires were 3.6 for ASD, 2.7 for GDD, 1.8 for SLI and 0.6 for MD. Differences between these numbers were statistically significant $(\mathrm{p}<0.05)$.

Conclusion Because of the high predictive value of the K-ASQ, a detailed evaluation is necessary for children suspected of developmental delay in an infantile health promotion system.
\end{abstract}

Key Words Developmental disorder, Screening test, K-ASQ

Received July 16, 2011; Accepted September 16, 2011

Corresponding author: Ha Ra Jeon

Department of Physical Medicine and Rehabilitation, National Health Insurance Corporation, Ilsan Hospital, 1232, Baeseok-dong, Ilsandong-gu, Goyang 410-719, Korea

Tel : +82-31-900-0361, Fax : +82-31-900-3343, E-mail : snoopyhara@hanmail.net

(c) This is an open-access article distributed under the terms of the Creative Commons Attribution Non-Commercial License (http://creativecommons. org/licenses/by-nc/3.0) which permits unrestricted noncommercial use, distribution, and reproduction in any medium, provided the original work is properly cited.

Copyright $\odot 2011$ by Korean Academy of Rehabilitation Medicine 


\section{INTRODUCTION}

Development is the process in which a child acquires daily living skills and continually adapts itself to different situations. It can be defined as the maturation of the central nervous system and as the structuralization of cognitive, psychological and behavioral functions interlocked with physical, biological and environmental factors. ${ }^{1}$ Developmental disorders, which include both developmental delay and deviation, refer to children who are mentally or physically inhibited for their ages; these problems affect 5 to $10 \%$ of children. ${ }^{2,3}$ Developmental disorders are caused by various factors, but can be prevented or minimized through early detection and intervention. Accordingly, many studies have been conducted to detect developmental disorders in their early stages. As a result, various diagnostic tools have been developed and applied. ${ }^{4-6}$

The Ages and Stages Questionnaire (ASQ) is suitable for cases of suspected developmental disorders, and has the merit of being inexpensive and easy-to-answer. ${ }^{7}$ The ASQ is intended for children aged 60 months or less, and is completed by the parents. It consists of 5 domains (communication, gross motor, fine motor, problem solving and personal-social) and each domain consists of 6 questions. The questionnaires are classified according to age. Points obtained from each domain are compared to a cutoff threshold of two standard deviations and the cutoff threshold is used to distinguish normal from suspected developmental delay.

In Korea, the Korean Ages and Stages Questionnaire (K-ASQ) has been standardized and applied clinically. ${ }^{8}$ In particular, the K-ASQ has been used to screen for developmental delays in the national child health checkup program, which commenced on November 15, 2007. Children suspected of a developmental delay on the K-ASQ questionnaire are referred to specialized clinics. ${ }^{9}$ However, a nationwide system managing suspected developmental delay children has not yet been established in Korea, and studies on evaluation of such referred children are lacking.

This study analyzed results of an in-depth evaluation of children referred to our hospital after being categorized as 'suspected developmental delay' or 'reevaluation required' on the Infantile Health Promotion System. We wanted this study to provide a basis for establishing a clinical management system for such children.

\section{MATERIALS AND METHODS}

\section{Subjects}

This study included 78 children, 62 boys $(79.4 \%)$ and 16 girls (20.5\%), who were referred to our hospital after being categorized as 'suspected developmental delay' or 'reevaluation required' in the infantile health promotion system between January 2008 and March 2011. Their average age was 27.2 months (9-61 months).

\section{Methods}

Examinations were performed by physiatrists, pediatric psychiatrists and pediatric neurologists according to a diagnostic protocol. In addition to physical and neurologic examinations, speech, language and cognitive evaluations were performed. When necessary, hearing tests, brain MRI scans and chromosome tests were performed and the children were subsequently categorized using etiological and clinical diagnoses.

K-ASQ: Due to the long time interval between referral and the actual visit to our clinic, the K-ASQ survey was re-conducted, again according to the child's current age. The questionnaire was filled out by parents or foster parents. The cut-off threshold was defined as a score that was below two standard deviations from the mean. Cases that fell short of the threshold were classified as 'suspected developmental delay', and scores that came close to the threshold were classified as 'reevaluation required.'

Speech and language evaluation: Speech and language evaluations were performed using the Sequenced Language Scale for Infants (SELSI) or the Preschool Receptive-Expressive Language Scale (PRES). ${ }^{10,11}$ Language delay was defined as a disparity of more than two standard deviation between linguistic and chronological age on SELSI, or when more than one year of delay was detected on PRES.

Cognitive evaluation: Cognitive evaluation was performed using the Bayley Scales of Infant Development II (BSID-II), the Korean Wechsler Preschool and Primary Scales of Intelligence (K-WPPSI) or the Korean Wechsler Intelligence Scales of Children-III (K-WISC III). ${ }^{12,13}$

Diagnostic classification: The children were diagnostically classified as specific language impairment 
(SLI), global developmental delay (GDD), intellectual disability, cerebral palsy, motor developmental delay (MD) or as autistic spectrum disorder (ASD). SLI was diagnosed when the developmental delay was confined to language, and not to cognition or motor and social function. In addition, performance intelligence had to be 85 or higher on the Wechsler scales, and the psychomotor developmental index (PDI) 70 or higher on the Bayley scale. Intellectual disability was diagnosed when the intelligence quotient was less than 70 , and borderline intelligence was also categorized as intellectual disability. The Bayley test was used as a substitute when the Wechsler test could not be performed and a diagnosis of GDD was included in the intellectual disability group. ASD included cases with problems in language and social function, and included autism, pervasive developmental disorder and Asperger syndrome. Children who did not show pervasive problems in development and who were not diagnosed with cerebral palsy, but were having significant problems in motor function, were diagnosed with MD after taking into account motor function domains of the Bayley test. ${ }^{14}$

Statistical analysis: Statistical analyses was performed using SPSS PC 16.0. The chi-square test was used to analyze differences in K-ASQ domains amongst the diagnostic groups (GDD, SLI, ASD and MD). Intergroup characteristics were analyzed by one-way ANOVA. The significance level was defined as p-values that were less than 0.05

\section{RESULTS}

It took an average of 6.5 days (0-24 days) for the children to visit our hospital's Developmental Delay Clinic after abnormalities on the Infantile Health Promotion System screening and subsequent referral.

Of a total of 78 children, $45(57.6 \%)$ had risk factors related to development. Among them, 34 (43.6\%) had neonatal risk factors such as premature birth, jaundice, meconium aspiration, septicemia and multifetal gestation. The other 11 (14.1\%) had perinatal risk factors including pre-eclampsia, gestational diabetes and drug use. In particular, 11 (15.2\%) were born prematurely, and 18 (23.1\%) had a family history of developmental delay, language delay, mental retardation or autism.

Of 78 children referred to this hospital, 72 were ultimately diagnosed with neurodevelopmental diseases and 6 were concluded to be normal. Thus, the positive predictive value of the K-ASQ was $92.3 \%$. Of the final diagnoses, GDD accounted for the highest proportion (30; $38.4 \%)$, followed by SLI $(28 ; 35.8 \%)$, MD $(9 ; 11.5 \%)$ and ASD (5; 6.4\%) (Fig. 1).

The five domains of the K-ASQ among the four diagnoses were analyzed. Communication, gross motor and personal-social domains among the four groups showed statistically significant differences $(\mathrm{p}<0.05)$ (Table 1) whereas fine motor and problem solving domains did not (Table 1). Of children with ASD, $100 \%$ showed abnormalities in the communication domain, in contrast to a mere $11 \%$ in the MD group. However, approximately $80 \%$ of children with MD and only $10 \%$ of children with

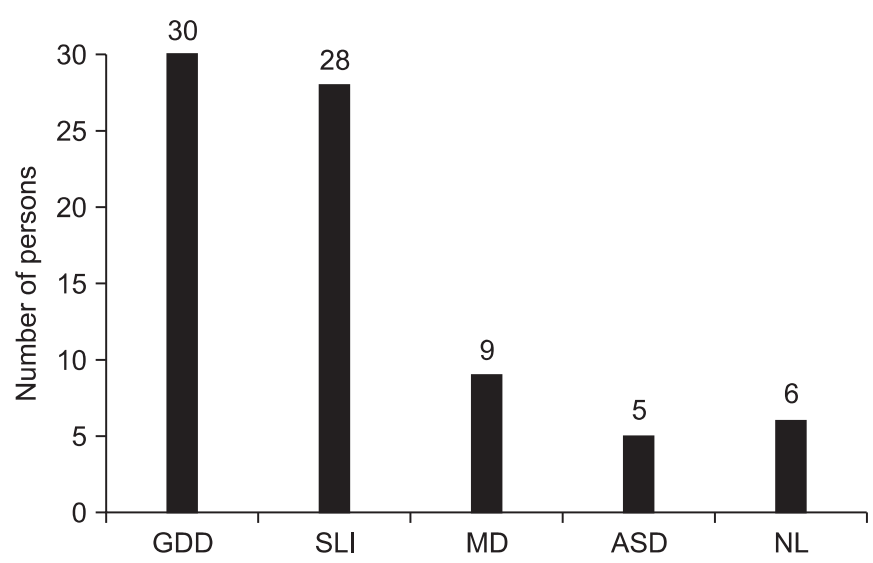

Fig. 1. The final diagnosis of children referred for suspected developmental delay. GDD: Global developmental delay, SLI: Specific language impairment, MD: Motor developmental delay, ASD: Autism spectrum disorder, NL: Normal.

Table 1. Abnormal Pattern of K-ASQ Scores According to the Diagnosis

\begin{tabular}{lccccc}
\hline & Comm & GM & FM & Solve & P-S \\
\hline GDD & $66.7^{*}$ & $46.7^{*}$ & 43.3 & 63.3 & $56.7^{*}$ \\
SLI & $78.6^{*}$ & $10.7^{*}$ & 21.4 & 57.1 & $25.0^{*}$ \\
ASD & $100^{*}$ & $40.0^{*}$ & 60.0 & 80.0 & $80.6^{*}$ \\
MD & $11.1^{*}$ & $77.8^{*}$ & 22.2 & 22.2 & $22.2^{*}$ \\
\hline
\end{tabular}

Values are percentages (\%)

GDD: Global developmental delay, SLI: Specific language impairment, ASD: Autism spectrum disorder, MD: Motor developmental delay, Comm: Communication, GM: Gross motor, FM: Fine motor, Solve: Problem solving skill, P-S: Personal-social interaction ${ }^{*} \mathrm{p}<0.05$ by $\kappa^{2}$-test 
Table 2. Numbers of Abnormal Domains According to the Diagnosis

\begin{tabular}{cccccccc}
\hline & \multicolumn{1}{c}{ Numbers of abnormal domains on the K-ASQ } \\
\cline { 2 - 8 } & $\mathbf{0}$ & $\mathbf{1}$ & $\mathbf{2}$ & $\mathbf{3}$ & $\mathbf{4}$ & $\mathbf{5}$ & Average \\
\hline $\begin{array}{c}\text { GDD } \\
\text { (n=30) }\end{array}$ & 2 & 3 & 10 & 4 & 7 & 4 & $2.7^{*}$ \\
$\begin{array}{c}\text { SLI } \\
(\mathrm{n}=28)\end{array}$ & 5 & 7 & 6 & 6 & 3 & 1 & $1.8^{*}$ \\
$\begin{array}{c}\text { ASD } \\
(\mathrm{n}=5)\end{array}$ & 0 & 0 & 0 & 3 & 1 & 1 & $3.6^{*}$ \\
$\begin{array}{c}\text { MD } \\
(\mathrm{n}=9)\end{array}$ & 0 & 6 & 0 & 1 & 1 & 0 & $0.6^{*}$ \\
\hline
\end{tabular}

GDD: Global developmental disorder, SLI: Specific language impairment, ASD: Autism spectrum disorder, MD: Motor developmental delay

${ }^{*} \mathrm{p}<0.05$ by ANOVA

SLI showed abnormal scores in the gross motor domain. In the personal-social domain, the ASD group, the SLI group and the MD showed abnormal scores in $80 \%, 20 \%$ and $20 \%$ of the children, respectively.

For each diagnosis, a score defined by the number of abnormal domains was calculated. The ASD group got the highest score, 3.6, followed by the GDD group with 2.7, the SLI group with 1.8 and the MD group with 0.6. Thus, there were significant intergroup differences (Table 2) $(\mathrm{p}<0.001)$.

\section{DISCUSSION}

Early detection and intervention are crucial in preventing and minimizing developmental disorders. Developmental disorders may occur at any stage of development, and thus it is advisable for the child to undergo checkups periodically. ${ }^{15-18}$ Many studies have been conducted to develop screening tools for highrisk children, ${ }^{4-7}$ and the Ages and Stages Questionnaire (ASQ) and the Denver Developmental Screening Test (DDST) have been used as standardized tools in Korea. ${ }^{4,8}$ In particular, the K-ASQ does not require training and is easily completed within 10 to 15 minutes by parents. Furthermore, its accuracy in identifying high risk children with developmental delay has been proven through many studies. ${ }^{3,4,19-23}$ As a result, the K-ASQ has been used as a screening tool in the infantile health promotion system, a nationwide project that commenced on November 15 ,
2007. This study includes data of children referred to our hospital within three years since the commencement of this nationwide project.

In this study, most of the children referred showed abnormal results after an in-depth evaluation at our clinic, and thus a high positive predictive value of K-ASQ was identified. Skellern et al. reported that the positive predictive value of the ASQ reached $40 \%$, but Lindsay et al. reported that it reached 85 to $92 \%{ }^{15,24}$ In this study the positive predictive value was $92.3 \%$. However, the value measured in this study, might be overstated to some extent in that a checkup was not done for all the children judged abnormal by the initial K-ASQ done during the Infantile Health Promotion System screening. Moreover, parents may have chosen to forgo referrals and further evaluations despite abnormal results on the initial K-ASQ. However, the results of this study imply that it is necessary to perform in-depth evaluations on children judged abnormal on screening tests such as the K-ASQ.

In this study, over half of the children referred to our hospital were found to have risk factors, unlike normal children. In particular, $15.2 \%$ of the children were born prematurely, which is a high percentage when compared to the $3.93 \%$ rate of infants in the general population that were born prematurely between 1995 and $2007 .{ }^{25}$ In common with previous studies, this study re-confirmed the high incidence of neurodevelopmental disorders in cases with existing risk factors such as premature birth.

Not many studies have been conducted on the family history of neurodevelopmental disorders. In Korea, a study reported that approximately $4.3 \%$ of children with ASD had a positive family history. ${ }^{26}$ In this study, $23.1 \%$ of the children had a positive family history where a parent, sibling or relative was diagnosed with motor function or language delay, which implies that developmental disorders are to some extent heritable.

In this study, the four diagnoses showed different but distinctive abnormalities in the five domains of the K-ASQ. Many of the children showing global delays in development such as those in the GDD or ASD groups, were found to have abnormal results in all five domains of the K-ASQ. Children with selective delays such as SLI and MD group members, tended to have language and gross motor problems, respectively.

This study has limitations in that it did not include the whole cohort that underwent the Infantile Health 
Promotion System screening program. Due to this limitation, sensitivity and specificity K-ASQ could not be calculated. In this regard, a post management system of those previously screened under the Infantile Health Promotion System needs to be established and further epidemiologic research or cohort studies through registration of children with risk factors is necessary.

\section{CONCLUSION}

This study shows that many of the children referred after Infantile Health Promotion System screening were found to have neurodevelopmental disorders. Early detection and intervention is crucial in improving prognosis in children with neurodevelopmental disorders. Accordingly, it is clinically important to accurately diagnose, through in-depth medical evaluations, children with suspected developmental delay. Furthermore, establishing a post-test management system after Infantile Health Promotion System screening is essential.

\section{REFERENCES}

1. Cho SC. Child psychiatry perspectives on developmental disorders. J Korean Acad Rehab Med 2006; 30 : 303-308

2. Woo YJ. Concept of developmental disability and the role of a pediatrician. Korean J Pediatr 2006; 49: 10311036

3. Kerstjens JM, Bos AF, ten Vergert EM, de Meer G, Butcher PR, Reijneveld SA. Support for the global feasibility of the Ages and Stages Questionnaire as developmental screener. Early Hum Dev 2009; 85: 443-447

4. Santos RS, Araujo AP, Porto MA. Early diagnosis of abnormal development of preterm newborns: assessment instruments. J Pediatr (Rio J) 2008; 84: 289-299

5. Regalado M, Halfon N. Primary care services promoting optimal child development from birth to age 3 years: review of the literature. Arch Pediatr Adolesc Med 2001; 155: 1311-1322

6. Frankenburg WK. Developmental surveillance and screening of infants and young children. Pediatrics 2002; 109: 144-145

7. Squires J, Potter L, Bricker D. The ASQ user's guide, 2nd ed, Baltimore: Brookes Publishing Company, 1999

8. Kim EY, Sung IK. The ages and stages questionnaire: screening for developmental delay in the setting of a pediatric outpatient clinic. Korean J Pediatr 2007; 50: 1061-1066

9. Eun BL, Kim SW, Kim YK, Kim JW, Moon JS, Park SK, Sung IK, Shin SM, Yoo SM, Eun SH, et al. Overview of national health screening program for infant and children. Korean J Pediatr 2008; 51: 225-232

10. Kim YT, Sung TJ, Lee YK. Preschool receptive-expressive language scale, 1st ed, Seoul: Seoul community rehabilitation center, 2003

11. Kim YT, Kim KH, Yoon HR, Kim HS. Sequenced language scale for infants, 1st ed, Seoul: Special Education Publisher, 2003

12. Bayley N. Bayley scales of infant development, 2nd ed, New York: The psychological Corporation, 1993

13. Park HW, Kwak GJ, Park KB. Korean-Wechsler preschool and primary scale of intelligence, 1st ed, Seoul: Special Education Publisher, 1998

14. Kim SW, Shin JB, Kim YH, Lee SK, Jung HJ, Song DH. Diagnosis and clinical features in children referred to developmental delay clinic. J Korean Acad Rehab Med 2004; 28: 132-139

15. Skellern CY, Rogers Y, O'Callaghan MJ. A parentcompleted developmental questionnaire: follow up of ex-premature infants. J Paediatr Child Health 2001; 37: $125-129$

16. Elbers J, Macnab A, McLeod E, Gagnon F. The ages and stages questionnaire: feasibility of use as a screening tool for children in Canada. Can J Rural Med 2009; 13: 9-14

17. Park CI, Park ES, Shin JC, Kim SW, Choi EH. Early treatment effect in children with cerebral palsy and delayed development. J Korean Acad Rehab Med 1999; 23: 1127-1133

18. Dawson G, Rogers S, Munson J, Smith M, Winter J, Greenson J, Donaldson A, Varley J. Randomized, controlled trial of an intervention for toddlers with autism: the Early Start Denver Model. Pediatrics 2010; 125: $17-23$

19. Squires J, Bricker D, Potter L. Revision of a parentcompleted development screening tool: ages and stages questionnaires. J Pediatr Psychol 1997; 22: 313328 
20. Klamer A, Lando A, Pinborg A, Greisen G. Ages and stages questionnaire used to measure cognitive deficit in children born extremely preterm. Acta Paediatr 2005; 94: 1327-1329

21. Richter J, Janson H. A validation study of the Norwegian version of the ages and stages questionnaires. Acta Paediatr 2007; 96: 748-752

22. Yu LM, Hey E, Doyle LW, Farrell B, Spark P, Altman DG, Duley L. Evaluation of the Ages and Stages Questionnaires in identifying children with neurosensory disability in the Magpie Trial follow-up study. Acta Paediatr 2007; 96: 1803-1808

23. Elbers J, Macnab A, McLeod E, Gagnon F. The Ages and Stages Questionnaires: feasibility of use as a screening tool for children in Canada. Can J Rural Med 2008; 13: 9-14

24. Lindsay NM, Healy GN, Colditz PB, Lingwood BE. Use of Ages and Stages Questionnaire to predict outcome after hypoxic-ischaemic encephalopathy in the neonate. J Paediatric Child Health 2008; 44: 590-595

25. Kim S, Lee JJ, Kim JH, Lee JH, Yun SW, Chae SA, Lim IS, Choi ES, Yoo BH. Changing patterns of low birth weight and associated risk factors in Korea, 19952007. Korean J Perinatol 2010; 21: 282-287

26. Kim MA, Kim SW, Kim YK, Chung HJ. Epilepsy, EEG abnormalities in children with autism spectrum disorders. J Korean Child Neurol Soc 2009; 17: 58-69 